Yüzüncü Yil Üniversitesi
Tarim Bilimleri Dergisi

Araştırma Makalesi (Research Article)

\title{
Melezleme ile Geliştirilmiş Bazı Aspir (Carthamus tinctorius L.) Genotiplerinin Tarımsal ve Teknolojik Özelliklerinin Belirlenmesi
}

\author{
Burhan ARSLAN ${ }^{1}$, Emrullah CULPAN ${ }^{* 2}$ \\ ${ }^{1,2}$ Tekirdağ Namık Kemal Üniversitesi, Ziraat Fakültesi, Tarla Bitkileri Bölümü, 59030, Süleymanpaşa, Tekirdağ \\ ${ }^{1}$ https://orcid.org/0000-0002-9728-4059 ${ }^{2}$ https://orcid.org/0000-0002-0702-7121 \\ *Sorumlu yazar e-posta: eculpan@nku.edu.tr
}

\section{Makale Bilgileri}

Geliş: 14.03 .2020

Kabul: 09.07.2020

Online Yayınlanma 31.12.2020

DOI: $10.29133 /$ yyutbd.703793

\section{Anahtar kelimeler}

Aspir,

Aspir 1slah1,

Melezleme,

Tohum verimi,

Yağ oran1.
Öz: 2017-2019 yılları arasında Tekirdağ Namık Kemal Üniversitesi Ziraat Fakültesi Tarla Bitkileri Bölümünde yürütülen bu çalışmada, melezleme ile geliştirilmiş aspir genotiplerinin bazı tarımsal ve teknolojik özelliklerinin belirlenmesi amaçlanmıştır. Bu amaçla Dinçer 5-18-1 aspir çeşidi ile PI 560161 genotipinin melezlenmesinden elde edilmiş 14 adet $F_{2}$ kademesindeki genotip materyal olarak kullanılmış ve 4 adet standart çeşit (Dinçer 5-18-1, Balcı, Linas ve Olas) ile karşılaştırılmıştır. Araştırmadan elde edilen bulgulara göre genotiplerin tohum verimi değerleri $98.23-171.26 \mathrm{~kg} / \mathrm{da}$, yağ oranı değerleri \% $30.87-36.66$ ve yağ verimi değerleri $33.44-55.80 \mathrm{~kg} / \mathrm{da}$ arasında değişmiş, geniş bir varyasyon göstermiştir. Araştırmada en yüksek yağ oranı ECBA-9 genotipinden (\%36.66) elde edilirken, en yüksek tohum verimi ve yağ verimi ECBA-13 genotipinden elde dilmiştir (sırasıyla 171.26 ve $55.80 \mathrm{~kg} / \mathrm{da}$ ). Yapılan bu çalışmada belirlenen 1slah amaçları doğrultusunda $F_{2}$ kademesindeki 5 adet genotipin (ECBA 6, 7, 9, 10 ve 13) diğer genotiplerden üstün olduğu görülmektedir. Ancak diğer genotipler ile birlikte $\mathrm{F}_{3}$ ve $\mathrm{F}_{4}$ generasyonlarında hem stabil olanlar hem de ümitvar olanlar belirlenecektir.

\section{Determination of Agricultural and Technological Traits of Some Safflower (Carthamus tinctorius L.) Genotypes Developed by Cross Breeding}

\section{Article Info}

Received: 14.03 .2020 Accepted: 09.07.2020

Online Published 31.12.2020

DOI: $10.29133 /$ yyutbd.703793

\section{Keywords}

Safflower,

Safflower breeding,

Cross breeding,

Seed yield,

Oil content.

\begin{abstract}
In this research, was conducted between 2017 and 2019 at Tekirdağ Namık Kemal University Agriculture Faculty Department of Field Crops, it was aimed to determine some agricultural and technological traits of safflower genotypes developed by cross breeding. For this purpose, $14 \mathrm{~F}_{2}$ genotypes obtained from a cross between Dinçer 5-18-1 cultivar and PI 560161 genotype were used as material and compared to 4 standard cultivars (Dinçer 5-18-1, Balc1, Linas and Olas). According to research findings, seed yield values of genotypes changed between $98.23-171.26 \mathrm{~kg} \mathrm{da}^{-1}$, oil content values $30.87-36.66 \%$ and oil yield values $33.44-55.80 \mathrm{~kg} \mathrm{da}^{-1}$ and showed a wide variation. The highest oil content was obtained from the ECBA-9 genotype (36.66\%), while the highest seed yield and oil yield were obtained from the ECBA-13 genotype (171.26 and $55.80 \mathrm{~kg} \mathrm{da}^{-1}$ respectively). In this study, it was determined that 5 genotypes (ECBA 6, 7, 9, 10 and 13) are superior of the other genotypes in $F_{2}$ generation. However, with the other genotypes, both stable and hopeful ones will be determined in the $\mathrm{F}_{3}$ and $\mathrm{F}_{4}$ generations.
\end{abstract}




\section{Giriş}

Asteraceae familyasından olan aspir bitkisi (Carthamus tinctorius L.) günümüzden 3000 yıl önce kültüre alınmaya başlanmış eski kültür bitkilerinden birisidir. Aspir, tohumlarında \%25-45 yağ bulunan, linoleik (omega 6) ve oleik (omega 9) olmak üzere iki ayrı tipi olan, yağı yemeklik olarak kullanılabilen, biyodizel üretimine uygun, küspesi ve karışım halinde ekimi hayvan yemi olarak değerlendirilen, kuraklığa dayanıklı, kışlık ve yazlık formları bulunan alternatif bir yağ bitkisidir (Arslan ve ark., 2012; Arslan ve Culpan, 2018).

Ülkemiz uzun yıllardır yağlı tohumlu bitkilerin üretimi ve tüketimi bakımından dışa bağımlı durumdadır. Ülkemiz tarımsal alanda birçok üründe yeterli üretimine karşın özellikle yağlı tohumlar ve bitkisel yağ üretiminde büyük dış ticaret açığg vermektedir. TÜİK' in dış ticaret verilerine göre, Türkiye 2019 yılında 1.8 milyar \$ değerinde yağlı tohum, 929 milyon \$ değerinde ham yağ ve 572 milyon \$ değerinde küspe olmak üzere toplam 3.3 milyar \$ ithalat yapmıştır (Anonim, 2019). Bu ithalat rakamları 2019 yılı ülkemiz toplam ithalatının (202.7 milyar \$) yaklaşık \% 1.62'sini oluşturmakta bu da ülke ekonomimiz açısından ciddi bir döviz kaybı anlamına gelmektedir. Türkiye'de üretilen yağlı tohumlardan (2019 yılı itibarıyla yaklaşık 4 milyon ton) elde edilen bitkisel yağ miktarı son yıllarda 700-900 bin ton arasında değişmekte olup bu değer ülke ihtiyacımızın ancak 1/3'ünü karşılayabilmektedir.

2018 verilerine göre Dünyadaki aspir ekiliş alanı yaklaşık 700000 ha, üretim 627653 ton ve verim ise $90 \mathrm{~kg} / \mathrm{da}$ 'dır. En fazla üretime sahip ülkeler Kazakistan, ABD, Meksika, Hindistan ve Türkiye şeklinde sıralanmaktadır (Anonim, 2018). Ülkemizde 2019 yılı verilerine göre 15860 ha alandan 21 883 ton aspir üretilmiş, ortalama verim $138 \mathrm{~kg} / \mathrm{da}$ olmuştur (Anonim, 2019).

Yerli tohumluk olarak ülkemizde tescil edilmiş 15 adet (Yenice 5-38, Dinçer 5-18-1, Remzibey05, Balc1, Linas, Olas, Göktürk, Asol, Hasankendi, Yekta, Zirkon, Olein, Koç, Safir, Servetağa) aspir çeşidi vardır. Islah amaçları doğrultusunda, geliştirilen aspir ç̧eşit ve hatlarının farklı çevre koşullarında stabil bir üretime izin verecek şekilde adaptasyon yeteneğinin ve verim performansının yüksek olması gerekmektedir. Dünyada olduğu gibi ülkemizde de aspir çeşitleri (15 adet) olmasına rağmen ülkemizde görülen farklı iklim ve toprak özelliklerinden dolayı ve her yıl giderek artan bitkisel yağ açığına bağlı olarak çeşit sayısının artırılmasına ihtiyaç duyulmaktadır. Ülkemizde özellikle 2014 yılına kadar aspir ekim alanlarında önemli artışlar olmuş fakat bu yıldan sonra tekrar dalgalı bir seyir izlemiştir. Ülkemiz hemen hemen her bölgesinde aspir tarımının yapılmasına elverişli olmasına rağmen, ekim alanlarında ve üretiminde önemli artışlar görülmemiştir.

Aspirde en önemli ıslah amaçları arasında; yüksek tohum verimi, yüksek yağ içeriği, düşük kabuk oranı, yüksek linoleik ve yüksek oleik asidi oranı, hastalık ve zararlılara karşı dayanıklılık ile soğuğa dayanıklılık sayılabilir. Fakat temel hedef, yüksek tohum verimi ve yağ oranı olmalıdır. Ayrıca sağlık açısından oleik tip yağlara olan ilginin artmasıyla beraber linoleik tip aspir çeşitleri yanında yüksek oleik asitli (High-Oleic) aspir çeşitlerin de geliştirilmesine ihtiyaç vardır. Bu doğrultuda, 1slah çalışmalarıyla geliştirilmiş olan hatların adaptasyon yeteneğinin ve verim performansının istenilen düzeyde olması gerekmektedir. Ülkemizde birçok ıslah çalışması yapılmış ve yapılmaya da devam edilmektedir (Uysal ve ark., 2006; Erbaş, 2012; Kaya ve ark., 2015).

Bu araştırmada, dikensiz Dinçer 5-18-1 aspir çeşidi ile yüksek yağ içeriğine sahip dikenli PI 560161 aspir genotipi gibberellik asit ile kimyasal polen kısırlığı yöntemi uygulanarak melezlenmiş ve ilk açılım kuşağı olan $\mathrm{F}_{2}$ kademesindeki döllerden yüksek tohum verimi ve yağ oranına sahip genotipler elde edilmeye çalışılmıştır.

\section{Materyal ve Yöntem}

\subsection{Araştırma yerinin ilkim ve toprak özellikleri}

Araştırma, Tekirdağ Namık Kemal Üniversitesi Ziraat Fakültesi Tarla Bitkileri Bölümü araştırma deneme arazisinde yazlık ekim yapılarak tek lokasyonda (Tekirdağ), 2017-2019 yılları arasında yürütülmüştür. Araştırma yerinin toprakları killi bir bünyeye sahip olup, pH'sı hafif alkali (7.1) ve organik madde bakımından düşük (\%0.98) seviyededir. Kireç içeriği düşük olan toprakların $(\% 2.35)$, fosfor seviyesi de düşük ( $4.12 \mathrm{~kg} / \mathrm{da})$ olup, tuzluluk problemi yoktur. $\mathrm{F}_{2}$ genotiplerinin yetiştirildiği 2019 yılında ortalama sıcaklık değerleri uzun yıllar ortalamasına yakın değerler göstermiştir. Toplam yağış 
miktarı ise $100.3 \mathrm{~mm}$ ile uzun yıllar ortalamaları toplamından az iken, ortalama oransal nem değerleri ise uzun yıllar ortalamasına yakın değerlerdedir (Çizelge 1). Aspir bitkisi iklim ve toprak istekleri bakımından çok seçici olmamasıyla bilinen bir yağ bitkisidir. Bu sebeple deneme yerinin iklim ve toprak koşulları aspir tarımı için yeterli ve uygundur.

Çizelge 1. Tekirdă̆ (Merkez)'ın aspir yetiştirme aylarına ait 2019 yılı ve uzun yıllar iklim verileri*

\begin{tabular}{lcccccc}
\hline \multirow{2}{*}{ Aylar } & \multicolumn{2}{c}{ Ortalama Sicaklık $\left({ }^{0} \mathrm{C}\right)$} & \multicolumn{2}{c}{ Toplam Yağ Ş $_{(\mathrm{mm})}$} & \multicolumn{2}{c}{ Oransal Nem $(\%)$} \\
& 2019 & Uzun Y1llar & 2019 & Uzun Yillar & 2019 & Uzun Yıllar \\
\hline Nisan & 11.6 & 11.7 & 42.9 & 40.8 & 71.9 & 77.0 \\
Mayıs & 17.9 & 16.7 & 31.2 & 36.6 & 70.5 & 76.3 \\
Haziran & 24.1 & 21.1 & 7.5 & 37.9 & 64.8 & 72.3 \\
Temmuz & 23.9 & 23.6 & 18.7 & 24.2 & 64.9 & 68.7 \\
Ağustos & 25.2 & 23.8 & 0 & 15.4 & 62.3 & 69.2 \\
Ort./Top. & 20.54 & 19.38 & 100.30 & 154.90 & 68.66 & 72.70 \\
\hline
\end{tabular}

*Tekirdağ Meteoroloji İstasyonu Verileri.

\subsection{Materyal}

Araştırmada, Eskişehir Geçit Kuşağı Tarımsal Araştırma Enstitüsü tarafından geliştirilmiş olan Dinçer 5-18-1 ve Balcı çeşidi, Trakya Tarımsal Araştırma Enstitüsü tarafından geliştirilmiş olan Linas ve Olas çeşidi ile Amerika Birleşik Devletleri Tarım Bakanlığı'ndan (USDA) temin edilen PI 560161 nolu genotip materyal olarak kullanılmıştır. Melezlemede materyal olarak kullanılmış olan Dinçer 5-181 çeşidi dikensiz yapıya sahip olup linoleik tip, kırmızı çiçekli ve yağ oranı \%25-30 civarındadır. PI 560161 genotipi ise dikenli yapıya sahip, linoleik, sarı çiçekli ve yağ oranı \%34-37 arasındadır.

\subsection{Yöntem}

2017 yılında Dinçer 5-18-1 çeşidi (†) ile PI 560161 genotipi (đ) melezlenmiş ve bu melezlemeden elde edilen $F_{1}$ genotipleri bir sonraki yıl ekilerek $F_{2}$ genotipleri elde edilmiştir (Şekil 1).

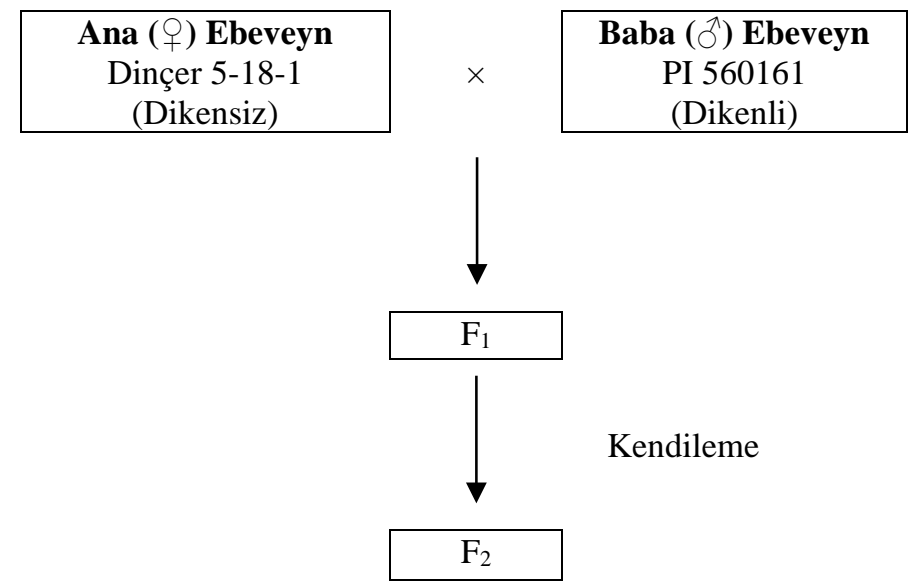

Şekil 1. Ebeveynlerin melezleme ve kendileme aşamaları.

07.03.2017 tarihinde $5 \mathrm{~m}$ uzunluğundaki sıralara $50 \mathrm{~cm}$ sıra arası ile ekilmiş olan Dinçer 5-181 ve PI 560161 ebeveynleri arasında haziran ayı içerisinde gibberellik asit ile kimyasal erkek kısırlık (ch-ms) oluşturularak melezleme yapılmıştır (Erbaş, 2007). Melezlenmiş olan her tabladan elde edilen tohumlar 01.08.2017 tarihinde ayrı ayrı hasat edilmiş ve $+4{ }^{\circ} \mathrm{C}$ 'de buzdolabında muhafaza edilmiştir. 18.04.2018 tarihinde, $F_{1}$ tohumları ekilerek $F_{1}$ bitkileri yetiştirilmiş ve çiçeklenme dönemi boyunca dikensiz olduğu tespit edilen bitkiler (melez olmayanlar) sıralardan uzaklaştırılmış ve böylece sıralarda gerçek melezlerin (\% 100) kalması sağlanmıştır. Aspirde dikenlilik karakteri dikensizlik üzerine baskındır ve kalıtımı tek bir gen tarafından kontrol edilmektedir (Baydar ve Erbaş, 2016). Gerçek melez $F_{1}$ genotiplerinden elde edilmiş bitkiler izole edilerek kendilenmiş, tarımsal ve teknolojik özellikleri 
belirlenecek 14 adet $\mathrm{F}_{2}$ genotipi oluşturulmuştur. Oluşturulmuş bu genotipler ile standart çeşitler (Dinçer 5-18-1, Balcı, Linas ve Olas) karşılaştırılmıştır.

19.04.2019 tarihinde 14 adet $F_{2}$ genotipi ve standart çeşitler kullanılarak kurulmuş deneme, 'Tesadüf Blokları Deneme Deseni'ne göre 3 tekrarlamalı olarak yürütülmüştür. Denemede her genotip 4 m uzunluğundaki parsellere sıra arası $20 \mathrm{~cm}$ (Arslan ve Culpan, 2018), ekim derinliği 3-4 cm olacak şekilde 4 sira halinde elle ekilmiştir. Toprak analiz sonucuna göre dekara $10 \mathrm{~kg}$ saf azot ve $6 \mathrm{~kg}$ saf fosfor verilmiştir. Azotun yarısı ekimle beraber diğer yarısı bitkiler sapa kalktı̆̆ında, fosforun ise tamamı ekimle birlikte verilmiştir. Hasat 05.08.2019 tarihinde elle yapılmıştır. Olgunlaşma ile birlikte parsellerden tesadüfen seçilen 10 bitkide bazı tarımsal ve teknolojik ölçümler yapılmıştır. Bu kapsamda araştırmada, bitki boyu (cm), dal sayısı (adet) tabla sayısı (adet), tabla çapı (cm), 1000 tane ağırlığı $(\mathrm{g})$, tohum verimi $(\mathrm{kg} / \mathrm{da})$, kabuk oranı $(\%)$, yağ oranı $(\%)$, yağ verimi $(\mathrm{kg} / \mathrm{da})$ ve yağ asitleri kompozisyonu (\%) gibi karakterler ölçülmüştür.

Araştırmada yă̆ içeriği, Nükleer Manyetik Rezonans (NMR) cihazında \% olarak okutularak belirlenmiştir. Tohumlar $70{ }^{\circ} \mathrm{C}$ 'de 48 saat etüvde bekletilerek nemi giderilmiştir. Nemi alınan 4 'er g tohum NMR cihazında her parselde 3 okuma yapılarak \% yağ oranı ortalaması hesaplanmıştır. Yağ asitleri kompozisyonu ise alev iyonlaşma detektörüne (FID-Flame Ionization Dedector) sahip gaz kromotografisi (Agilent 7820A) cihazında yapılmıştır. Yağların metillendirilmesi için soğuk pres tekniği ile elde edilmiş $1 \mathrm{mg}$ ham yağ üzerine $0.5 \mathrm{ml}$ metanollü potasyum hidroksit koyulup çalkalanmıştır. Daha sonra bu karışımın üzerine $10 \mathrm{ml}$ n-heptan eklenerek çözelti tekrar çalkalanmış ve gliserolün ayrılmasıyla çözelti bulanıklaşmıştır. 1 saat bekledikten sonra gliserolün çökelmesiyle beraber oluşan faz ayrımında üst faz metil esterleri alınarak Gaz Kromatografi (GC) cihazına direk olarak verilmiş ve analiz yapılmıştır. Yağ asitlerine ilişkin kromatogramlar elde edilerek palmitik $\left(\mathrm{C}_{16: 0}\right)$, stearik $\left(\mathrm{C}_{18: 0}\right)$, oleik $\left(\mathrm{C}_{18: 1}\right)$ ve linoleik $\left(\mathrm{C}_{18: 2}\right)$ yağ asitlerinin \% oranları tespit edilmiştir. $\mathrm{GC}$ cihazının çalışma koşulları aşağıda verilmiştir. Elde edilen kromotogramlardaki pikler ticari standart yağ asidi metil ester karışımına (Sigma, Supelco® 37 Component FAME Mix) göre isimlendirilmiştir.

\begin{tabular}{|c|c|}
\hline Cihaz & Agilent 7820A GC \\
\hline Dedektör Tipi & FID - Alev İyonizasyon Dedektörü \\
\hline Kullanılan Kolon & J\&A 112-88A7 (100 m × 0.25 mm, $0.2 \mu \mathrm{m})$ \\
\hline Enjektör Sıcaklığı & $250^{\circ} \mathrm{C}$ \\
\hline Dedektör Sicaklığı & $280^{\circ} \mathrm{C}$ \\
\hline Enjektör Kapasitesi & $\begin{array}{l}1 \mu \mathrm{m} \\
\text { Hidrojen (40 mL/dk) }\end{array}$ \\
\hline Gaz Hizları & $\begin{array}{l}\text { Hava }(450 \mathrm{~mL} / \mathrm{dk}) \\
\text { Helyum }(30 \mathrm{~mL} / \mathrm{dk})\end{array}$ \\
\hline Firın S1caklı̆̆ 1 & $\begin{array}{l}120^{\circ} \mathrm{C} \text { 'de } 1 \mathrm{dk} \text { bekledikten sonra } 175^{\circ} \mathrm{C} \text { 'ye } 10^{\circ} \mathrm{C} / \mathrm{dk} \text { artışla ulaşıyor. } 175 \\
{ }^{\circ} \mathrm{C} \text { 'de } 10 \mathrm{dk} \text { bekliyor. } 5^{\circ} \mathrm{C} / \mathrm{dk} \text { artışla } 210^{\circ} \mathrm{C} \text { 'ye ulaşıyor. Bu sıcaklıkta } 5 \mathrm{dk} \\
\text { bekliyor. } 5^{\circ} \mathrm{C} / \mathrm{dk} \text { artışla } 230^{\circ} \mathrm{C} \text { 'e ulaşıor. Bu sıklıkta da } 5 \mathrm{dk} \text { bekliyor }\end{array}$ \\
\hline
\end{tabular}

\subsection{Verilerin değerlendirilmesi}

Araştırma sonucundan elde edilen veriler tesadüf blokları deneme desenine göre varyans analizine tabi tutulmuştur. Ortalamalar arasındaki farklılıkların önem düzeyini belirlemek için Duncan Testi (\%5) kullanılmıştır. Verilerin analizinde TARIST istatistiki analiz programından faydalanılmıştır.

\section{Bulgular ve Tartışma}

Aspir genotiplerinin bitki boyu değerleri $58.93-77.70 \mathrm{~cm}$ arasında değişmiş ve geniş bir varyasyon göstermiştir. En uzun bitki boyuna Dinçer 5-18-1 çeşidi sahip olurken $(77.70 \mathrm{~cm})$, melez genotiplerden ise en uzun bitki boyu ECBA-4 genotipinden elde edilmiştir $(73.92 \mathrm{~cm})$. Aspirde bitki boyu eklemeli genler tarafindan kontrol edildiğinden dolayı (Pahlavani ve ark., 2007) yapılan birçok çalışmada aspirde bitki boyunda geniş bir varyasyon olduğu bildirilmektedir. Aspirde bitki boyu arttıkça yatma sorunu ortaya çıkmakta ve ideal bitki boyunun $60-80 \mathrm{~cm}$ arasında olduğu bildirilmektedir (Emongor, 2010). Yapılan araştırmalarda aspirde bitki boyunun lokasyon, iklim koşulları ve çeşitlere 
göre değişiklik gösterdiği bildirilmiştir. Arslan (2007b) 12 aspir genotipinde bitki boyunun 51.7-73.7 $\mathrm{cm}$ arasında, Deshmuk ve ark. (2008) $54 \mathrm{~F}_{1}$ populasyonunda bitki boyunun 75.2-125.2 cm arasinda değiştiğini belirlemişlerdir.

Dal sayısı bakımından genotipler incelendiğinde en fazla dal sayısı Balcı çeşidi ve ECBA-12 genotipinden elde edilmiştir (sırasıyla 6.15 ve 6.08 adet/bitki). Aspir bitkisinde dal sayısı tabla sayısı ile doğru orantılıdır ve tabla sayısının artması doğrudan tohum verimini etkilemektedir (Arslan ve Culpan, 2018). Ayrıca aspirde dal sayısı çevre koşulları ve genetik faktörlerden etkilenen bir özelliktir. Erbaş (2012) aspirde dal sayısı için kalıtım derecesinin \% 64.2 oranında olduğunu bildirmiştir. Aspirde ideal dal sayısının 6-8 adet/bitki olduğu rapor edilirken, yapılan bazı araştırmalarda Çamaş ve Esendal (2006) 3-9 adet, Arslan (2007a) 5.8-8.9 adet olduğunu bildirmişlerdir. Bu sonuçlar çalışmamızla paralellik göstermektedir.

Tabla sayıs1 aspirde tohum verimini belirleyen en önemli 1slah kriterlerinden biridir (Weiss, 2000). Tabla sayısı bakımından genotipler arasında en yüksek tabla sayısı ECBA-11 (14.50 adet/bitki) genotipinden elde edilmiş, en düşük tabla sayısı ise ECBA-2 (8.05 adet/bitki) genotipinde gözlemlenmiştir (Tablo 2). Yaptıkları araştırmalarda Erbaş (2007) tabla sayısının 48 aspir genotipinde 7.2-18.0 adet/bitki olduğunu, Kaya ve ark. (2015) yazlık ekilen aspirde tabla sayısının 3.98-6.0 adet/bitki olduğunu saptamışlardır. Araştırma sonuçları ile diğer araştırmacıların sonuçları arasındaki farklılığın genotip ve ilgili araştırmaların yapıldığı lokasyonların iklim farklılığından kaynaklandığg söylenebilir.

Tablo 2. Genotiplerin bazı tarımsal ve kalite özellikleri

\begin{tabular}{|c|c|c|c|c|c|c|c|c|c|c|}
\hline No & Genotipler & $\begin{array}{l}\text { Bitki } \\
\text { Boyu } \\
(\mathrm{cm}) \\
\end{array}$ & $\begin{array}{c}\text { Dal } \\
\text { Say1sı } \\
\text { (adet) }\end{array}$ & $\begin{array}{l}\text { Tabla } \\
\text { Say1s1 } \\
\text { (adet) } \\
\end{array}$ & $\begin{array}{l}\text { Tabla } \\
\text { Çap1 } \\
(\mathrm{cm}) \\
\end{array}$ & $\begin{array}{c}1000 \text { Tane } \\
\text { Ağgrliğ } \\
\text { (g) }\end{array}$ & $\begin{array}{l}\text { Tohum } \\
\text { Verimi } \\
\text { (kg/da) }\end{array}$ & $\begin{array}{c}\text { Kabuk } \\
\text { Oranı } \\
(\%) \\
\end{array}$ & $\begin{array}{c}\text { Yağ } \\
\text { Oranı } \\
(\%) \\
\end{array}$ & $\begin{array}{c}\text { Yağ } \\
\text { Verimi } \\
\text { (kg/da) }\end{array}$ \\
\hline 1 & ECBA-1 & $72.90 \mathrm{ab}$ & $5.78 \mathrm{a}-\mathrm{c}$ & $10.63 \mathrm{bc}$ & $2.04 \mathrm{~g}$ & 37.90 ef & $106.02 \mathrm{~h} 1$ & $43.43 \mathrm{f}-\mathrm{h}$ & 35.00 bc & 37.11 g-1 \\
\hline 2 & ECBA-2 & $71.30 \mathrm{bc}$ & $3.67 \mathrm{e}$ & $8.05 \mathrm{c}$ & $2.04 \mathrm{~g}$ & $35.20 \mathrm{f}$ & 98.231 & 45.55 b-e & 34.04 de & 33.441 \\
\hline 3 & ECBA-3 & $58.63 \mathrm{e}$ & $5.25 \mathrm{~cd}$ & $9.80 \mathrm{bc}$ & $2.44 \mathrm{bc}$ & $41.83 \mathrm{~b}-\mathrm{d}$ & $114.40 \mathrm{gh}$ & 45.70 b-d & $31.251-\mathrm{k}$ & 35.74 g-1 \\
\hline 4 & ECBA-4 & $73.92 \mathrm{ab}$ & $4.83 \mathrm{~d}$ & $9.05 \mathrm{c}$ & 2.34 c-e & $42.15 \mathrm{~b}-\mathrm{d}$ & $121.03 \mathrm{fg}$ & 46.42 a-c & $30.87 \mathrm{k}$ & 37.36 g-1 \\
\hline 5 & ECBA-5 & 69.87 bc & $3.75 \mathrm{e}$ & 8.82 c & $2.27 \mathrm{~d}-\mathrm{f}$ & 37.73 ef & $129.64 \mathrm{~d}-\mathrm{f}$ & $42.58 \mathrm{f}-\mathrm{h}$ & 33.34 ef & 43.23 c-e \\
\hline 6 & ECBA-6 & $71.80 \mathrm{ab}$ & $5.23 \mathrm{~cd}$ & 9.92 bc & $2.39 \mathrm{~b}-\mathrm{d}$ & 42.82 bc & 144.51 bc & $44.55 \mathrm{c}-\mathrm{f}$ & 32.32 gh & 46.70 bc \\
\hline 7 & ECBA-7 & $58.93 \mathrm{e}$ & $3.73 \mathrm{e}$ & 10.15 bc & 2.35 c-e & 40.12 c-e & $151.81 \mathrm{ab}$ & $42.88 \mathrm{f}-\mathrm{h}$ & 31.64 h-k & $48.03 \mathrm{~b}$ \\
\hline 8 & ECBA-8 & 69.85 bc & 5.93 a-c & $9.73 \mathrm{bc}$ & $2.49 \mathrm{ab}$ & $38.73 \mathrm{e}$ & $118.25 \mathrm{f}-\mathrm{h}$ & $42.93 \mathrm{fg}$ & 31.77 g-j & 38.24 f-h \\
\hline 9 & ECBA-9 & $60.00 \mathrm{e}$ & 5.95 a-c & 9.88 bc & $2.15 \mathrm{fg}$ & $35.18 \mathrm{f}$ & $114.88 \mathrm{gh}$ & 40.421 & $36.66 \mathrm{a}$ & $42.11 \mathrm{~d}-\mathrm{f}$ \\
\hline 10 & ECBA-10 & $65.95 \mathrm{~cd}$ & $4.83 \mathrm{~d}$ & 10.82 bc & $2.62 \mathrm{a}$ & 42.88 bc & 136.09 c-e & 41.63 g-1 & $35.58 \mathrm{ab}$ & $48.42 \mathrm{~b}$ \\
\hline 11 & ECBA-11 & 69.41 bc & $6.06 \mathrm{ab}$ & $14.50 \mathrm{a}$ & $2.02 \mathrm{~g}$ & 37.97 ef & $125.00 \mathrm{e}-\mathrm{g}$ & $44.00 \mathrm{~d}-\mathrm{f}$ & 32.00 g-1 & 39.97 e-g \\
\hline 12 & ECBA-12 & $72.58 \mathrm{ab}$ & $6.08 \mathrm{a}$ & $8.93 \mathrm{c}$ & $2.08 \mathrm{~g}$ & 39.60 de & 124.84 e-g & $46.90 \mathrm{ab}$ & 31.98 g-1 & $39.92 \mathrm{e}-\mathrm{g}$ \\
\hline 13 & ECBA-13 & 60.92 de & $5.40 \mathrm{a}-\mathrm{d}$ & $8.50 \mathrm{c}$ & $2.58 \mathrm{a}$ & $46.87 \mathrm{a}$ & $171.26 \mathrm{a}$ & 45.72 b-d & $32.58 \mathrm{fg}$ & $55.80 \mathrm{a}$ \\
\hline 14 & ECBA-14 & $71.40 \mathrm{bc}$ & $5.23 \mathrm{~cd}$ & $12.50 \mathrm{ab}$ & $2.23 \mathrm{ef}$ & $41.85 \mathrm{~b}-\mathrm{d}$ & 143.69 b-d & $48.67 \mathrm{a}$ & 31.87 g-1 & $45.79 \mathrm{~b}-\mathrm{d}$ \\
\hline 15 & Dinçer 5-18-1 & $77.70 \mathrm{a}$ & $5.28 \mathrm{~b}-\mathrm{d}$ & $8.47 \mathrm{c}$ & $2.27 \mathrm{~d}-\mathrm{f}$ & $44.38 \mathrm{ab}$ & $122.68 \mathrm{e}-\mathrm{g}$ & $43.95 \mathrm{~d}-\mathrm{f}$ & 28.121 & $34.49 \mathrm{~h} 1$ \\
\hline 16 & Balc1 & 68.45 bc & $6.15 \mathrm{a}$ & $8.90 \mathrm{c}$ & $2.42 \mathrm{bc}$ & 42.87 bc & 139.05 b-d & $44.70 \mathrm{~b}-\mathrm{f}$ & $31.00 \mathrm{jk}$ & 43.12 b-e \\
\hline 17 & Linas & $71.53 \mathrm{~b}$ & $4.85 \mathrm{~d}$ & $10.07 \mathrm{bc}$ & $2.60 \mathrm{a}$ & 46.65 a & 145.05 bc & $43.15 \mathrm{fg}$ & $32.56 \mathrm{fg}$ & 47.31 bc \\
\hline 18 & Olas & $70.67 \mathrm{bc}$ & $4.67 \mathrm{~d}$ & $8.80 \mathrm{c}$ & $2.49 \mathrm{ab}$ & $44.18 \mathrm{ab}$ & 145.83 bc & $40.77 \mathrm{~h} 1$ & $34.50 \mathrm{~cd}$ & $50.33 \mathrm{ab}$ \\
\hline & Genotip & $* *$ & $* *$ & $* *$ & $* *$ & $* *$ & $* *$ & $* *$ & $* *$ & $* *$ \\
\hline & $\mathrm{CV}$ & 8.57 & 16.64 & 19.50 & 8.70 & 8.85 & 14.26 & 5.20 & 6.10 & 14.71 \\
\hline
\end{tabular}

**: \%1 düzeyinde önemli, aynı harfle gösterilen ortalamalar arasında fark bulunmamaktadır.

Tabla çapı ile tohum verimi, tabladaki tohum sayısı, bin tane ağırlığı ve yağ içeriği arasında pozitif bir korelasyon mevcuttur (Çamaş ve ark., 2005). Araştırmada tabla çapı değerleri 2.02-2.62 cm arasında değişmiş ve en yüksek tabla çapı ECBA-10 ve ECBA-13 genotipi ile Linas çeşidinden elde dilmiştir (Tablo 2). Arslan (2007b) tabla çapını 2.5-3.2 cm, Çamaş ve Esendal (2006) ise tabla çapının 1.5-2.1 cm arasında olduğunu bildirmişlerdir. Elde edilen sonuçlar ile araştırmacıların sonuçları uyum içindedir. Ayrıya Erbaş (2007) aspirde tabla çapının değişen çevre koşullarından kolaylıkla etkilenebileceğini bildirmiştir.

Aspirde tohum verimini belirleyen en önemli seleksiyon kriterlerinden biri de 1000 tane ağırlığıdır (Weiss, 2000). 1000 tane ağırlığının yüksek olması ileri generasyon hatların belirlenmesine yardımcı olacaktır. Ayrıca aspirde 1000 tane ağırlığı yüksek kalıtım derecesi gösterdiğinden dolayı, bu kriter bakımından yapılacak seleksiyonlarda yüksek tohum verimine sahip hatların oluşturulmasına dolaylı olarak katkı sağlayacaktır (Pahlavani ve ark., 2007). Çalışmamızda en yükssek 1000 tane ağırlığı ECBA-13 genotipi ve Linas çeşidinden elde edilmiş (sırasıyla $46.87 \mathrm{~g}$ ve $46.65 \mathrm{~g}$ ), buna karşın en düşük 
1000 tane ağırlığı ECBA-2 ve ECBA-9 genotiplerinden elde edilmiştir (Tablo 2). Yapılan araştırmalarda 1000 tane ağırlığını Erbaș (2007) 33.6-52.1 g arasında, Safavi ve ark. (2011), 17.8-46.0 g arasında, Kaya ve ark. (2015) 39.9-46.6 g arasında, Culpan ve Arslan (2018) 40.90-54.95 g arasında değiştiğini bildirmişlerdir. Elde edilen sonuçlar literatürde belirtilen araştırıcıların sonuçları ile uyum içindedir.

Aspir genotiplerinin tohum verimi değerleri $98.23-171.26 \mathrm{~kg} / \mathrm{da}$ arasında değişmiş ve en yüksek tohum verimi ECBA-13 genotipinden elde dilmiştir (171.26 kg/da). Aspirde en önemli 1slah amac1 tohum verimini artırmaktır. Aspirde tohum veriminin kalıtımında birçok eklemeli gen etkili olduğu için düşük bir kalıtım derecesi göstermektedir (Weiss, 2000; Erbaş, 2012). Ayrıca tohum verimi, bir çeşit özelliği olmakla beraber ekolojik faktörlerden ve kültürel uygulamalardan önemli derecede etkilenmektedir (Siddiqui ve Oad, 2006). Tohum verimi ile tabla çapı, tabla sayısı ve tabladaki tohum sayısı arasında pozitif ve önemli korelasyon olduğu birçok araştırıcı tarafından bildirmiştir (Çamaş ve Esendal, 2006; Arslan, 2007b; Omidi ve ark, 2012). Çamaş ve Esendal (2006) yaptıkları çalışmada aspirde tohum verimi değerlerinin 46.0-298.0 kg/da arasında değiștiğini, Erbaş ve ark. (2016), tohum veriminin 15.2-215.9 kg/da arasında değiştiğini bildirmişlerdir. Arslan ve Culpan (2018) 45 aspir çeşit ve genotipinde tohum verimi değerlerinin $14.79-234.99 \mathrm{~kg} / \mathrm{da}$ arasında değiştiğini saptamışlardır. Bu araştırmalara ilaveten Şenateş ve Erbaş (2020) $\mathrm{F}_{8}$ generasyonuna kadar tek tohum nesli seleksiyon yöntemi ile ulaştırılan 68 adet hattın tohum veriminin 30.2-252.6 kg/da arasında değiştiğini bildirmişleridir. Ayrıca sonbaharda ekilen aspirlerin tohum veriminin ilkbaharda ekilenlerden daha yüksek olduğu rapor edilmiştir (Johnson ve ark., 2011).

Aspir tohumlarında kabuk oranı arttıkça iç oranı azalmakta ve dolayısıyla yağ içeriği düşmektedir (Mündel ve Bergman, 2010). Bu sebeple tohum kabuğu inceliği aspirde aranan bir seleksiyon kriteridir. Yapılan çalışmada genotiplerin kabuk oranı \% 40.42-48.67 arasında değişmiştir. En düşük kabuk oranı ECBA-9 genotipinden elde edilirken (\% 40.42), en yüksek kabuk oranı ECBA14 genotipinde (\% 48.67) tespit edilmiştir. Rudra Naik ve ark. (2009) $F_{2}$ ve $F_{3}$ generasyonlarında kabuk oranı üzerine çevre etkisinin az olduğunu ve oluşan çeşitliliğin genetik faktörlerin sebep olduğunu bildirmişlerdir. Saisanthosh ve ark. (2018) yaptıkları çalışmada 57 aspir genotipinde kabuk oranının \%29.50-62.43 arasında değiştiğini bildirmişlerdir. İnce kabuklu tohumlara sahip aspir genotiplerinin seçilmesi ileri generasyonlarda ümitvar hatların oluşturtulmasına katkı sağlayacaktır.

Aspirde bir diğer önemli ıslah amacı tohumun yă̆ içeriğini artırmaktır. Aspir genotiplerinin yağ oranları incelendiğinde en yüksek yağ oranı ECBA-9 genotipinden (\% 36.66), en düşük yağ oranı Dinçer 5-18-1 çeşidinden elde edilmiştir (\% 28.12). Melez genotiplerde ise en düşük yağ içeriği ECBA-4 genotipinde (\% 30.87) saptanmıştır (Tablo 2). Nabloussi ve ark. (2008) yaptıkları çalışmada 212 aspir hattından 181 tanesinin çimlendiğini ve bu çimlenen aspir hatlarının ortalama yağ oranının \% 23.3647.53 arasında değiştiğini bildirmişlerdir. Kobuk ve ark. (2019) bazı aspir hat ve çeşitlerinde yaptıkları çalışmada yağ oranının \% 25.78-35.16 arasında değiştiğini saptamışlardır. Araştırmada kabuk oranının artmasıyla yă̆ oranının düştüğü dikkati çekmektedir (Tablo 2). Nitekim yapılan araştırmalarda da kabuk oranı ile yağ oranı arasında negatif korelasyon olduğu bildirilmektedir (Arslan, 2007a). Dolayısıyla ince kabuklu ve yağ oranı yüksek hatların ileri generasyonlara aktarılması gerekmektedir. Ayrıca Şenateş ve Erbaş (2020) aspirde yağ oranının yüksek oranda kalıtım derecesi gösterdiğini ve genotiplerde belirlenen yağ oranının olası bir yabancı döllenme olmadığı takdirde ileri generasyonlara aktarılabileceğini bildirmiş̧lerdir.

Yağ verimi, yağ bitkileri 1slahında göz önünde bulundurulması gereken önemli bir kriterdir. Yağ verimini, tohum verimi ve yağ oranı belirlemektedir. Yapılan araştırmada yağ verimi değerleri geniş bir varyasyon göstermiş ve $33.44-55.80 \mathrm{~kg} / \mathrm{da}$ arasında değişmiştir. En yüksek yağ verimi değeri ECBA-13 genotipinden elde edilmiştir (Tablo 2). Kaya ve ark. (2015) aspirde yağ verimi değerlerinin 37.0-48.9 $\mathrm{kg} / \mathrm{da}$ arasında değiştiğini, Arslan ve Culpan (2018) yaptıkları çalışmada bu değerlerin 1.3-67.97 kg/da arasında olduğunu rapor etmişlerdir. Ayrıca aspirde yağ verimi değerlerinin ekolojik koşullardan kolaylıkla etkilenebileceği bildirilmiştir (Erbaş, 2012).

Aspir, yağlı tohumlar arasında yağ asitleri komposizyonu bakımından geniş varyasyona sahip bir bitkidir. Aspir genotiplerinin yağ asitleri kompozisyonu Tablo 3 'te verilmiştir. Araştırma sonuçlarına göre standart çeşitlerin linoleik yağ asidi oranı \% 1 7.33-72.16 arasında, melez genotiplerin linoleik yă asidi oranı ise \% 65.78-72.31 arasında değişmiştir. ECBA genotiplerinin ana (Dinçer 5-18-1) ve baba (PI 560161) ebeveynleri linoleik tip olduğu için melez genotipler linoleik olmuş ve en yüksek linoleik yağ asidi içeriğine sahip genotip ECBA-11 olmuştur (\% 72.31). Joksimoviç ve ark. (2006), melez genotiplerde oleik asit oranının düşük olmasını, linoleik asitten sorumlu genlerin oleik asit üzerine 
baskın olduğundan dolayı olduğunu bildirmişlerdir. Ayrıca Golkar ve ark. (2011) oleik asidin kalıtımında eklemeli genlerin etkili olduğunu ve yüksek kalıtım derecesine sahip olduğunu bildirmişlerdir. Johnson ve ark. (1999) 797 adet aspir introdüksiyon materyalinde linoleik asidin \% 11.083.1, oleik asidin \% 6.2-81.9, palmitik asidin \% 3.9-6.8 ve stearik asidin \% 1.1-4.5 arasında olduğunu bildirmişlerdir. Erbaş ve ark. (2016) 39 aspir genotipinde, çalışmalarının ilk yılında \% 11.1-68.3 oleik asit ve \% 18.0-74.7 linoleik asit, ikinci y1lda ise \% 12.0-71.6 oleik asit ve \% 14.2-73.9 linoleik asit varyasyonu olduğunu bildirmişlerdir. Arslan ve Culpan (2018) yaptıkları çalışmada 45 aspir genotipinde oleik asit oranının \% 13.97-74.74 arasında, linoleik asit oranının ise \% 12.21-69.83 arasında değiştiğini rapor etmişlerdir. Araştırmadan elde edilen sonuçlar literatürde belirtilen araştırıcıların sonuçları ile uyum içinde olup, belirtilen varyasyon limitleri arasındadır.

Tablo 3. Genotiplerin yağ asitleri kompozisyonu

\begin{tabular}{|c|c|c|c|c|c|c|}
\hline \multirow[b]{2}{*}{ No } & \multirow[b]{2}{*}{ Genotip } & \multicolumn{5}{|c|}{ Yağ Asitleri Komposizyonu (\%) } \\
\hline & & $\begin{array}{c}\text { Oleik } \\
\text { C }_{18: 1}\end{array}$ & $\begin{array}{c}\text { Linoleik } \\
\text { C }_{18: 2}\end{array}$ & $\begin{array}{c}\text { Palmitik } \\
\text { C }_{16: 0}\end{array}$ & $\begin{array}{c}\text { Stearik } \\
\mathrm{C}_{18: 0}\end{array}$ & $\begin{array}{c}\text { Diğer } \\
\text { Yağ Asit. }\end{array}$ \\
\hline 1 & ECBA-1 & 14.66 & 68.87 & 10.62 & 2.15 & 3.70 \\
\hline 2 & ECBA-2 & 16.16 & 69.14 & 8.17 & 3.02 & 3.51 \\
\hline 3 & ECBA-3 & 18.33 & 70.04 & 7,25 & 1.89 & 2.49 \\
\hline 4 & ECBA-4 & 14.50 & 68.98 & 9.63 & 2.58 & 4.31 \\
\hline 5 & ECBA-5 & 18.26 & 65.78 & 10.19 & 3.08 & 2.69 \\
\hline 6 & ECBA-6 & 14.85 & 70.45 & 10.12 & 2.50 & 2.08 \\
\hline 7 & ECBA-7 & 16.14 & 70.38 & 10.40 & 1.96 & 1.12 \\
\hline 8 & ECBA-8 & 15.00 & 69.68 & 10.74 & 2.14 & 2.44 \\
\hline 9 & ECBA-9 & 15.33 & 69.45 & 10.26 & 2.10 & 2.86 \\
\hline 10 & ECBA-10 & 15.20 & 70.56 & 10.19 & 2.55 & 1.50 \\
\hline 11 & ECBA-11 & 11.98 & 72.31 & 11.17 & 3.00 & 1.54 \\
\hline 12 & ECBA-12 & 13.55 & 72.25 & 8.70 & 2.67 & 2.83 \\
\hline 13 & ECBA-13 & 14.76 & 68.74 & 11.77 & 2.49 & 2.24 \\
\hline 14 & ECBA-14 & 14.50 & 70.64 & 9.50 & 2.65 & 2.71 \\
\hline 15 & Dinçer 5-18-1 & 16.27 & 72.16 & 7.41 & 2.23 & 1.93 \\
\hline 16 & Balcı & 15.85 & 70.63 & 6.54 & 2.00 & 4.98 \\
\hline 17 & Linas & 14.20 & 68.50 & 9.15 & 2.89 & 5.26 \\
\hline 18 & Olas & 68.46 & 17.33 & 7.85 & 2.99 & 3.37 \\
\hline
\end{tabular}

\section{Sonuç}

Son y1llarda tohum verimi (200-300 kg/da) ve yağ oranı (\%35-40) yüksek aspir çeşitleri geliştirilmiş olsa da üretim koşullarında verimlerin bu değerlerin çok altında kaldığı görülmektedir. Bu nedenle aspir tarımının yaygınlaştıılabilmesi ve diğer yağlı tohumlu bitkilerle (ayçiçeği, kanola) rekabet edebilmesi için ekolojik koşullara iyi adapte olabilen, stabil ve yağ oranı ile tohum verimi bakımından üstün olan yeni aspir hat ve çeşitlerin geliştirilmesi gerekmektedir. Yapılan bu çalışmada belirlenen 1slah amaçları doğrultusunda (yüksek tohum verimi ve yağ oranı) $\mathrm{F}_{2}$ kademesinde 5 adet genotipin (ECBA 6, 7, 9, 10 ve 13) diğer genotiplerden önde olduğu görülmektedir. Ancak diğer genotipler ile birlikte $F_{3}$ ve $F_{4}$ generasyonlarında hem stabil olanlar hem de ümitvar olanlar belirlenecektir.

\section{Kaynakça}

Anonim, (2019). TÜİK, Türkiye İstatistik Kurumu, https://biruni.tuik.gov.tr/medas/?kn=92\&locale=tr, Erişim tarihi: 27.02.2020.

Anonim, (2018). FAOSTAT, Food and Agriculture Organization of The United Nations Statistics Division, http://www.fao.org/faostat/en/\#data/QC, Erişim tarihi: 27.02.2020.

Arslan, B. (2007a). The path analysis of yield and its components in safflower (Carthamus tinctorius L.). Journal of Biological Science, 7 (4), 688-672.

Arslan, B. (2007b). Assessing of heritability and variance components of yield and some agronomic traits of different safflower (Carthamus tinctorius L.) cultivars. Asian Journal of Plant Sciences, 6 (3), 554-557. 
Arslan, B., Ateş, E., \& Coşkuntuna, L. (2012). Forage yield and some quality properties of safflower (Carthamus tinctorius L.)-fodder pea (Pisum arvense L.) mixtures, as affected by sowing rates in Tekirdag, Turkey. Romanian Agricultural Research, 29, 255-260.

Arslan, B., \& Culpan, E. (2018). Identification of suitable safflower genotypes for the development of new cultivars with high seed yield, oil content and oil quality. Azarian Journal of Agriculture, 5 (5), 133-141.

Baydar, H., \& Erbaş, S. (2016). Aspir (Carthamus tinctorius L.)'de verim, yağ ve oleik asit içeriği yüksek hat geliştirme 1slahı. Tarla Bitkileri Merkez Araştırma Enstitüsü Dergisi, 25 (Özel Sayl2), 155-161.

Culpan, E., \& Arslan, B. (2018). Salisilik asit uygulamasının aspir (Carthamus tinctorius L.) çeşitlerinin verim ve bazı kalite özelliklerine etkisinin araştıılması. Akademik Ziraat Dergisi, 7 (2), 173-178.

Çamaş, N., Ayan, A.K., \& Çırak, C. (2005, June). Relationships between seed yield and some characters of safflower (Carthamus tinctorius L.) cultivars grown in the Middle Black Sea conditions. VI. International Safflower Conference, İstanbul, Turkey.

Çamaş, N., \& Esendal, E. (2006). Estimates of broad-sense heritability for seed yield and yield components of safflower (Carthamus tinctorius L.). Hereditas, 143, 55-57.

Deshmukh, S.N., Lande, S.S., Potdukhe, N.R., Mahajan, P.V., Nandkhile, S., \& Wakode, M.M., (2008, November). Utilization of genetic male sterility system toward recurrent selection in safflower and genetic gain realized. 7th International Safflower Conference, Wagga Wagga, New South Wales, Australia.

Emongor, V. (2010). Safflower (Carthamus tinctorius L.) the underutilized and neglected crop: a review. Asian Journal of Plant Sciences, 9, 299-306.

Erbaş, S. (2007). Aspirde (Carthamus tinctorius L.) sentetik erkek kisirlı̆̆ tekniği ile elde edilmiş melez populasyonlarından hat geliştirme olanakları. Yüksek Lisans Tezi, Süleyman Demirel Üniversitesi, Fen Bilimleri Enstitüsü, Isparta, Türkiye.

Erbaş, S. (2012). Melezleme ıslahı ile tohum verimi, yağ ve oleik asit içeriği yüksek aspir (Carthamus tinctorius L.) hatlarının geliştirilmesi. Doktora Tezi, Süleyman Demirel Üniversitesi, Fen Bilimleri Enstitüsü, Isparta, Türkiye.

Erbaş, S., Tonguç, M., \& Şanlı, A. (2016). Variations in the agronomic and quality characteristics of domestic and foreign safflower (Carthamus tinctorius L.) genotypes. Turkish Journal of Field Crops, 21 (1), 110-119.

Golkar, P., Arzani, A., \& Rezaei, A.M. (2011). Genetic analysis of oil content and fatty acid composition in safflower (Carthamus tinctorius L.). Journal of the American Oil Chemists Society, 88, 975982.

Johnson, R.C., Bergman, J.W., \& Flynn, C.R. (1999). Oil and meal characteristics of core and non-core safflower accessions from the USDA collection. Genetic Resources and Crop Evolution, 46, 611-618.

Johnson, C., Petrie, S.E., Franchini, M.C., \& Evans, M. (2011). Yield and yield components of wintertype safflower. Crop Science, 52 (5), 2358-2364.

Joksimovic, J., Jovanka, A., Marinkovic, R., \& Jovanovic, D. (2006). Genetic control of oleic and linoleic acid contents in sunflower. Helia, 29 (44), 33-40.

Kaya, M., Bayramin, S., Kulan, E., \& Özaşık, İ. (2015). Bazı ileri aspir hatlarının Eskişehir koşullarındaki performansları. Uludă Üniversitesi Ziraat Fakültesi Dergisi, 29 (1), 57-66.

Kobuk, M., Ekinci, K., \& Erbaş, S. (2019). Aspir (Carthamus tinctorius L.) genotiplerinin fiziksel ve kimyasal özelliklerinin belirlenmesi. Kahramanmaraş Sütçü İmam Üniversitesi Tarım ve Doğa Dergisi, 22 (1), 89-96.

Mündel H.H., \& Bergman, J.W. (2010). Safflower. In J. Vollmann, \& I. Rajcan (Eds.), Oil Crops, Handbook of Plant Breeding (pp. 423-447). Verlag, Berlin: Springer.

Nabloussi, A., El Fechtali, M., \& Lyagoubi, S. (2008, November). Agronomic and technological evaluation of a world safflower collection in Moroccan conditions. 7th International Safflower Conference, Wagga Wagga, New South Wales, Australia.

Omidi, A.H., Khazaei, H., Monneveux, P., \& Stoddard, F. (2012) . Effect of cultivar and water regime on yield and yield components in safflower (Carthamus tinctorius L.). Turkish Journal of Field Crops, 17 (1), 10-15. 
Pahlavani, M.H., Saeidi, G., \& Mirlohi, A.F. (2007). Genetic analysis of seed yield and oil content in safflower using $\mathrm{F}_{1}$ and $\mathrm{F}_{2}$ progenies of diallel crosses. International Journal of Plant Production, 2, 129-140.

Rudra Naik, V., Bentur, G.M., Salimath, P.M., \& Parameshwarappa, K.G. (2009). Introgression of non spiny and high oil content in adapted generations of safflower (Carthamus tinctorius L.). Karnataka Journal of Agricultural Sciences, 22 (1), 39-43.

Safavi, S.A., Pourdad, S.S., Safavi, S.M., \& Safavi, A.S. (2011). Heritability and genetic gain of some morphological traits in safflower (Carthamus tinctorius L.). American Journal of Scientific Research, 17, 14-18.

Saisanthosh, K., Keshavulu, K., Joesph Raju, T., Palchamy, K., Mukta, N., \& Sultana, R. (2018). Variability studies for seed morphological traits in safflower genotypes. International Journal of Current Microbiology and Applied Sciences, 7 (10), 2204-2216.

Siddiqui, M.H., \& Oad, F.C. (2006). Nitrogen requirement of safflower (Carthamus tinctorius L.) for growth and yield traits. Asian Journal of Plant Sciences, 5 (3), 563-565.

Şenateş, A., \& Erbaş, S. (2020). Tek tohum nesli seleksiyon yöntemi ile geliştirilen aspir (Carthamus tinctorius L.) hatlarının tarımsal ve teknolojik özelliklerinin belirlenmesi. Süleyman Demirel Üniversitesi Fen Bilimleri Enstitüsü Dergisi, 24 (1), 143-151.

Uysal, N., Baydar, H., \& Erbaş, S. (2006). Isparta popülasyonundan geliştirilen aspir (Carthamus tinctorius L.) hatlarının tarımsal ve teknolojik özelliklerinin belirlenmesi. SDÜ Ziraat Fakültesi Dergisi, 11 (1), 52-63.

Weiss, E.A. (2000). Oilseed crops: Safflower (2nd ed.). Oxford: Blackwell Science. 